\title{
Agrobacterium-mediated stable transformation of medicinal plant Andrographis paniculata callus expressing $\beta$-glucuronidase (GUS) gene
}

\author{
Erly Marwani ${ }^{1 *}$, Agustina Tangapo ${ }^{2}$, Fenny Martha Dwivany ${ }^{1}$.
}

\author{
${ }^{1}$ School of Life Sciences and Technology, Institut Teknologi Bandung, Jalan Ganesha 10 Bandung 40132, \\ Indonesia \\ ${ }^{2}$ Department of Biology, Fac. of Mathematic and Natural Sciences, Universitas SamRatulangi Manado, \\ Indonesia
}

\begin{abstract}
This study was carried out to establish a stable genetic transformation in callus culture of Andrographis paniculata mediated by Agrobacterium tumefaciens. The leaf disks of $A$. paniculata were infected with $A$. tumefaciens LBA4404 carrying a binary vector pCAMBIA1304 that contain $\beta$-glucuronidase (GUS) and hygromycin phosphotransferase $(h p t)$ genes. The infection was conducted by dipping method for one hour, followed by co-cultivation in the dark for three days. To examine transient GUS expression, the co-cultivated leaf disks were assayed for $\beta$-glucuronidase activity and to obtain stable transformed callus, the co-cultivated leaf disks were selected on the callus induction medium which contain $20 \mathrm{mg} / 1$ hygromycin for selection. The transformed callus was periodically subcultured every three weeks into the fresh selection medium over the 15 weeks period. To test a stable transformation, the callus was subjected to PCR analysis for GUS gene detection. The results indicated that the co-cultivated leaf disks expressed GUS activity and proliferated to produce callus on the selective medium. Analysis of PCR on the transformed callus indicated the presence $976 \mathrm{bp}$ fragment that confirmed the presence of $\beta$-glucuronidase gene. These findings imply that the $\beta$-glucuronidase was stably integrated into A. paniculata callus culture.
\end{abstract}

Keywords: Andrographis paniculata, Agrobacterium tumefaciens, andrographollide, transformed callus, $\beta$-glucuronidase gene.

\section{Introduction}

Andrographis paniculata (Burm.f.) Wallich ex Ness has long been known as medicinal plant in southern Asia. Extract of this plant has shown pharmaceuticals properties such as anti-inflammatory, antipyretic, antibacterial, hepatoprotective, immunostimulant, antioxidants, anticancerous activity and anti-HIV (Niranjan et al., 2010; Zhang and Tan, 2000; Calabrese et al., 2000, Otake et al., 1995). The primary medicinal constituents of $A$. paniculata that is responsible for the

\section{*Corresponding author:}

Erly Marwani

School of Life Sciences \& Technology, Institut Teknologi Bandung, Jl. Ganesha 10 Bandung 40132, Indonesia. Phone/fax: 022-2500258/022-2534107, email: erly@sith.itb.ac.id pharmaceutical properties is andrographolide, a diterpene secondary metabolite.

In general, quantity of the plant secondary metabolites in nature is frequently inconsistent due to wide variation of environmental conditions at different location. This has prompted many scientists to consider the possibility of using in vitro plant tissue culture as an alternative sources for secondary metabolites production. Plant tissue culture such as cell culture and root culture have been developed as alternative sources to provide plant-specific valuable metabolites. This approach irrespective to environmental, ecological and climatic conditions. In addition, in vitro culture can proliferate the culture at higher growth rates than the whole plant in nature cultivation. 
However, our previous study indicated that production of andrographollide in cell and callus culture of $A$. paniculata demonstrated limited amount, only $0.49 \%$ in the callus culture and $0.23 \%$ in the cell culture. These amount of andrographolide were lower than that in original leaves plant which contain andrographollide as much as $2.3 \%$. Therefore, it is important to develop an additional technique in plant tissue culture to enhance the secondary metabolite, andrographollide, production.

Several studies reported that many efforts have been tried to enhance production of secondary metabolites in vitro such as precursor feeding, elicitation, and cell immobilization. However, limited success was achieved due to the complex regulation in secondary metabolite biosynthesis. On the other hand, several reports indicated that genetically engineered plant cell culture showed a potency for enhancing secondary metabolites production. This approach can be done by modifying the genes related to secondary metabolites biosynthesis in cell cultures. One such modification can be done by introducing a gene of interest into plant cells to increase the activity of specific enzymes which regulate the synthesis of desired secondary metabolites. This may help to increase secondary metabolites production in cell culture (Mulabagal and Tsay, 2004).

Introducing a gene into plant cell can be carried out directly by using particle bombardment or indirectly by using Agrobacterium tumefaciens as a vector. Among the available gene transfer systems, Agrobacterium-mediated gene transfer is considered as more efficient for stable integration of genes into plant genome (Vasudevan et al., 2007). However, there is little information concerning a genetic modification in A. paniculata. Thus, the purpose of this study was to develop genetic transformation method on A. paniculata which are mediated by Agrobacterium tumefaciens to obtain stable transformed callus. So that, the method can facilitate genetic transformation of A. paniculata generating stable transformant of callus or even whole plant.

\section{Materials and Methods Plant materials}

Andrographispaniculata (Burm.f.) Wallich ex Nees as the source of plant material was obtained from Balai Penelitian Tanaman Obat dan Rempah (Balitro) Bogor, West Java. The leaf explants (second to fourth leaf adjacent to the apical shoot bud) were used as explants for transformation. Intact leaves were surface-sterilized with $1.7 \%$ sodium hypochlorite containing 2 drops of Tween 20 for 10-15 $\mathrm{min}$, rinsed four times with sterile distilled water.

\section{Agrobacterium tumefaciens}

Agrobacterium tumefaciens strain LBA4404 harboring the binary vector pCAMBIA 1304 was used for transformation experiments. This vector carries the reporter gene for $\beta$-glucuronidase (GUS) and the selectable marker gene for hygromycin phosphotransferase $(h p t)$. For plant transformation, a single colony of the bacteria was inoculated into Luria Bertanie (LB) medium supplemented with kanamycin (25 $\mathrm{mg} / \mathrm{l})$ and rifampicillin (50 $\mathrm{mg} / \mathrm{l})$ and cultured overnight at $28^{\circ} \mathrm{C}$. The Agrobacterium cells, approximately $10^{6}$ cell $/ \mathrm{ml}$ medium $\left(\mathrm{OD}_{600 \mathrm{~nm}}\right.$ $=0.8$ ), were collected by centrifugation at 4,000 rpm for $20 \mathrm{~min}$ and resuspended in liquid half-strenght MS medium containing $100 \mu \mathrm{M}$ acetosyringone.

\section{Preculture, transformation and co- cultivation}

Leaves from 2-month-old plants were cut into $1 \times 1 \mathrm{~cm}$ (as leaf explants) and precultured on MS medium solidified with $0.8 \%(\mathrm{w} / \mathrm{v})$ agar contained $0.5 \mu \mathrm{M} 2,4-\mathrm{D}$ and $0.1 \mu \mathrm{M}$ BAP for three days at $28^{\circ} \mathrm{C}$. Afterwards, the leaf explants were dipped for $60 \mathrm{~min}$ in the A. tumefaciens suspension which was supplemented with $100 \mu \mathrm{M}$ acetosyringone and agitated at $100 \mathrm{rpm}$. Subsequently, the leaf explants were blotted 
on sterile filter paper and co-cultivated for three days in dark at $28^{\circ} \mathrm{C}$ on agar-solidified $(0.8 \% \mathrm{w} / \mathrm{v}) \mathrm{MS}$ medium supplemented with $100 \mu \mathrm{M}$ acetosyringone, $0.5 \mu \mathrm{M}$ 2.4-D and 0.1 $\mu \mathrm{M}$ BAP.

\section{Selection of transformant and subculture of transformed callus}

After 3 days of co-cultivation, explants were washed twice ( $5 \mathrm{~min}$, per wash) with sterile water containing $400 \mathrm{mg} / 1$ cefotaxime, blotted dry on sterile filter paper, and were then transferred on a selection medium (MS supplemented with $0.5 \mu \mathrm{M} 2.4-\mathrm{D}, 0.1 \mu \mathrm{M}$ BAP, $20 \mathrm{mg} / 1$ hygromycin and $400 \mathrm{mg} / 1$ cefotaxime). After three weeks in the dark at $28^{\circ} \mathrm{C}$, they were subcultured on the fresh selection medium without the addition of cefotaxime. The induced transformed callus was maintained on full-strength MS medium with the addition $5.0 \mu \mathrm{M}$ 2.4-D, $0.1 \mu \mathrm{M}$ BAP, and $20 \mathrm{mg} / 1$ hygromycin for cell proliferation. In order to continue the growth of callus and to obtain a stable transformed callus, the hygromycin resistantcallus was subsequently subcultured on the fresh selection medium at 3-weeks interval for five repeated subculture. During these treatments, only a small proportion of target cell typically received the inserted DNA and only a small proportion of these cells survived and grew to form a cell clones with stably integrated DNA fragments. In the process of subculture, the death tissues (necrosis) were removed, so that only the survived callus on the selection medium was transferred to the fresh medium. The growth of normal and transformed callus was observed by measuring their fresh weight. The collected data were plotted on a graph to obtain a growth curves of normal and transformed callus.

\section{GUS histochemical assay}

$\beta$-glucuronidase activity was detected by staining the co-cultivated leaf explants and the transformed callus with 5-bromo4-chloro-3indol- $\beta$-d-glucuronic acid (X-Gluc) as substrate as described by Jefferson (1987). The staining was performed by reacting the co-cutivated leaf explants and the transformed callus with a mixture of $1 \mathrm{mM} \mathrm{X-Gluc,} 0.1$ $\mathrm{mM} \mathrm{K}_{3} \mathrm{Fe}(\mathrm{CN})_{6^{\prime}} 0.1 \mathrm{mM} \mathrm{K} \mathrm{K}_{4} \mathrm{Fe}(\mathrm{CN})_{6^{\prime}}, 50 \mathrm{mM}$ fosfat buffer $\left(\mathrm{NaH}_{2} \mathrm{PO}_{4} / \mathrm{NaHPO}_{4}, \mathrm{pH} 7\right)$. The reaction was kept over night at $37^{\circ} \mathrm{C}$ in the dark condition. Following the reaction, the tested samples were soaked with 95\% methanol to remove any chlorophyll and others plant pigments. The GUS activity was observed visually by formation of blue color spots in the tissue that carries GUS gene. In this experiment, the T-DNA of pCAMBIA 1304 contained GUS gene with a size 976 bp and CamV35S promoter with a size 1866 bp CamV35S promoter. The GUS gene has an intron in the $\mathrm{N}$-terminal region of the coding sequence. This intron-gus reporter gene expresses GUS activity only in plant cell but not in the cell of $A$. tumefaciens (Ohta et al., 1990 in Hiei et al., 1994). Thus, blue spots staining only appeared on transformed plant tissue but not in cell of A. tumefaciens when those samples reacted with 5-bromo-4chloro-3indol- $\beta$-d-glucuronic acid (X-Gluc) as substrat.

\section{Molecular analysis of transformed callus by PCR}

Stable transformation of the callus was confirmed by detection of the GUS gene using PCR (Polymerase chain reaction) analysis on callus derived from transformed leaf disks. Putative transformed callus survived on medium containing hygromycin were randomly picked up to analyze whether the GUS gene has been inserted into the callus of A. paniculata. Total DNA was extracted individually from the callus based on the CTAB method with modification of Lodhi et al. (1994). For PCR analysis, the extracted genomic DNA was amplified using specific primers for the GUS gene (forward: 5' - CAA CGA ACT GAA CTG CAG - 3'; reverse : 5' GGC ACA GCA CAT CAA AGA GA - 3'). The reaction mixture for PCR was incubated in a DNA thermal cycler under the following 
conditions: initial denaturation at $94^{\circ} \mathrm{C}$ for 1 $\mathrm{min}$, followed by 25 cycles of denaturation at $94^{\circ} \mathrm{C}$ for 30 seconds, annealing at $62^{\circ} \mathrm{C}$ for 30 seconds, and extensions at $72^{\circ} \mathrm{C}$ for $3 \mathrm{~min}$, and final extensions at $72^{\circ} \mathrm{C}$ for 7 minutes. The PCR products were analyzed on $1.5 \%$ agarose gel electrophoresis with ethidium bromide and Tris-acetate-EDTA buffer followed by photographed under UV lamp at $\lambda 380 \mathrm{~nm}$.

\section{Result and discussion \\ Transformation and selection of putative transformed callus}

The method of co-cuntivation of three days in this experiments showed that the leaf disks could be successfully transformed. This was indicated that when the infected leaf discs cultured on medium containing selection agent (20 mg/1 hygromycin) could survive and dedifferentiated to produce callus from the cut edge. The transformed of leaf disks seem became resistance to hygromycin due to the vector of PCAMBIA 1304 that carried by A. tumefaciens has transferred the hpt gene (for resistance to hygromycin) into the genom of A. paniculata. On the other hand, uninfected leaf disks could not survive on the selection medium and eventually died (Figure 1 ). This results was in agreement with previous study that 1-3 days co-cultivation was the optimal time for higher plant transformation using A. tumefaciens (Boyko et al., 2009).

Of the total infected leaf disks (176), as much as 114 (64.4\% of frequencies) of the leaf explants produced hygromycin-resistant callus. This results indicated that the method of infection applied by dipping method and the addition of acetosyringon at the inoculation and co-cultivation steps was highly efficient in the process of T-DNA insertion to the plant cell of $A$. paniculata. Similar findings have been reported earlier by Hong et al. (2007), Li et al. (2007), and Sharma et al. (2009) for the efficiency of dipping method which followed by co-cultivation and the addition of acetosyringone in doing genetic transformation mediated by Agrobacterium. The addition of acetosyringone was reported to improve transformation efficiency as acetosyringone could activate the vir genes of Agrobacterium that were required to initiate the transformation process (Gelvin, 2000).

\section{Growth of the putative transformed callus}

The results showed that the growth of transformed callus was inhibited on the medium containing hygromycin but remain growing. This was indicated by slower growth of transformed callus compared to that of untransformed callus on medium without hygromycin (Figure 2). This was suspected that hygromycin caused stress to the growth of transformed callus and may induced secretion a substances such as phenolics that may inhibited the regeneration or proliferation of transformed cell. Consequently, the growth of the transformed callus decreased when compared to non-transformed callus. This results are consistent with the growth of transgenic Potato callus (Turhan, 2004). In
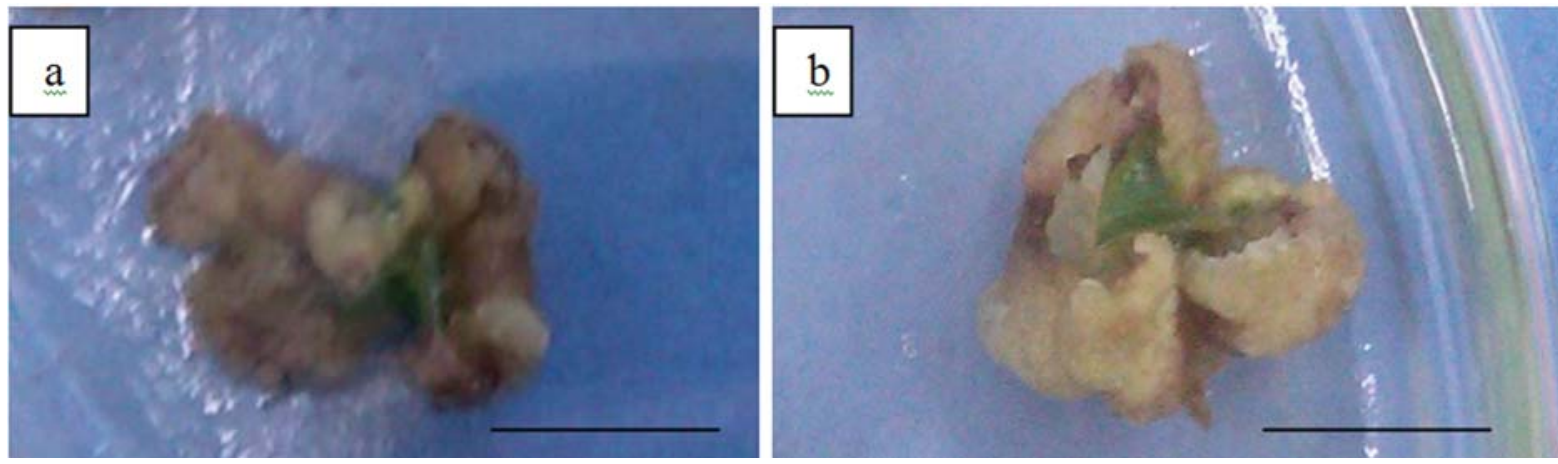

Figure 1. Non-transformed leaf disk (a) and transformed leaf disk which de-differentiate to produce callus (b) on the selection medium containing $2 \mathrm{mg} / 1$ hygromycin. Barr $=10 \mathrm{~mm}$ 


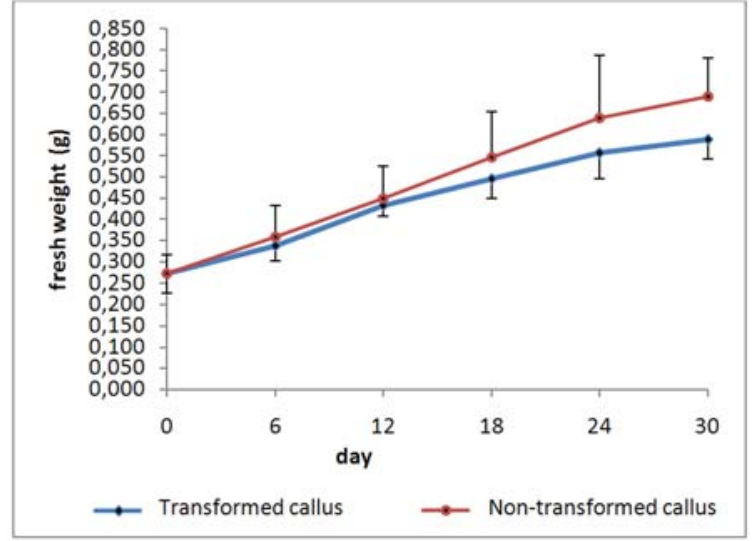

Figure 2. Growth curve of transformed callus on medium containing hygromycin and untransformed callus on medium without hygromycin

contrast, when untransformed callus placed on selection medium containing hygromycin, the untransformed callus could not survive and eventually died. The hygromycin resistant-callus was subsequently transferred on the selection medium for five repeated subculture. Eventhough the growth of transformed callus decreased but the callus remain growing on subculture-1, 2, 3, 4, and 5 (Figure 3). These results suggest that the $h p t$ gene has been inserted into callus, so that the callus has resistance to hygromycin that was contained in the selection medium.

\section{Expression of $\beta$-glucuronidase (GUS) in transformed tissue}

Detection of $\beta$-glucuronidase (GUS) expression can be used to indicate both transient and stable transformation (Serres et al., 1997). In present study, GUS activity was detected in leaf explants after three days of co-cultivation and in putative transformed callus on the subculture 1,2,3,4, and 5. The co-cultivated leaf explants exhibited GUS expression as indicated

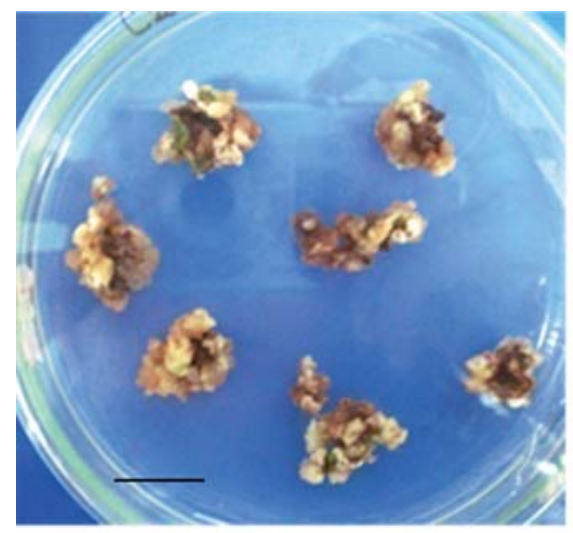

a

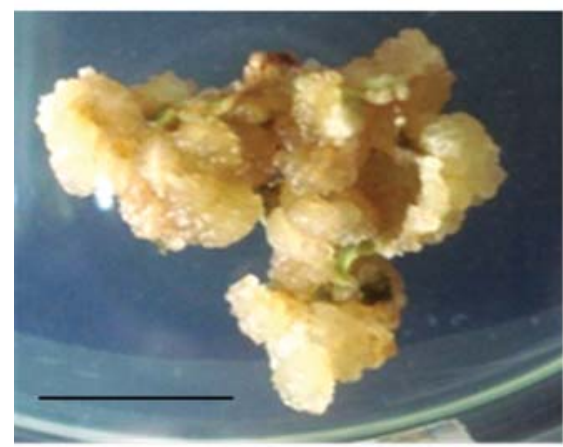

d

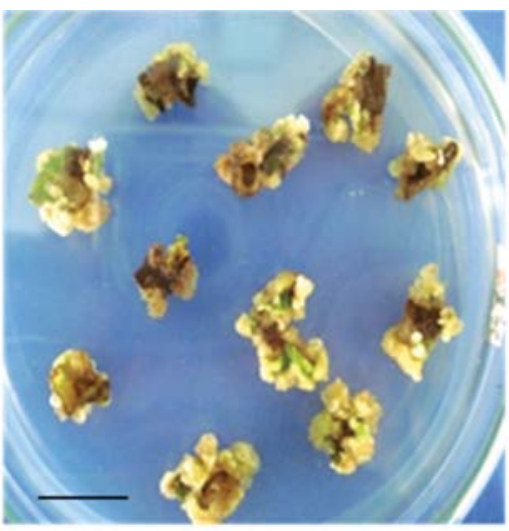

b

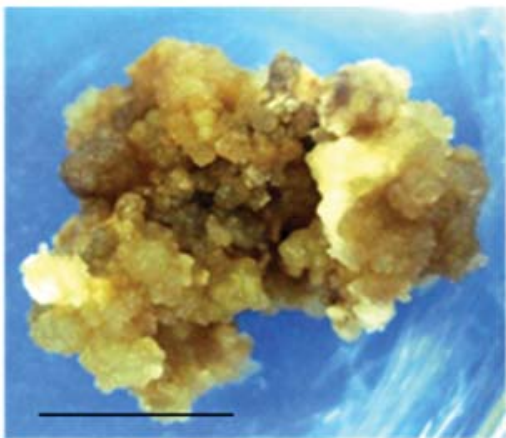

e

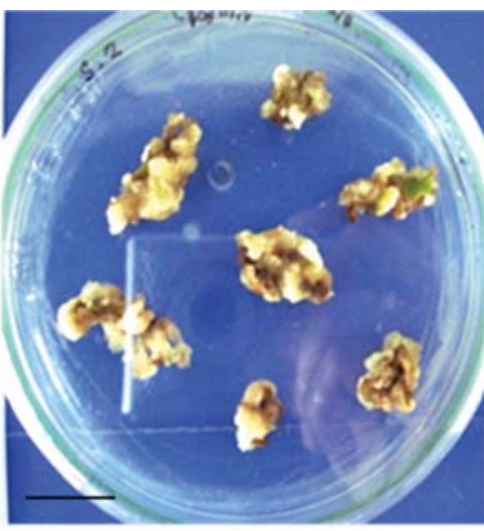

C.

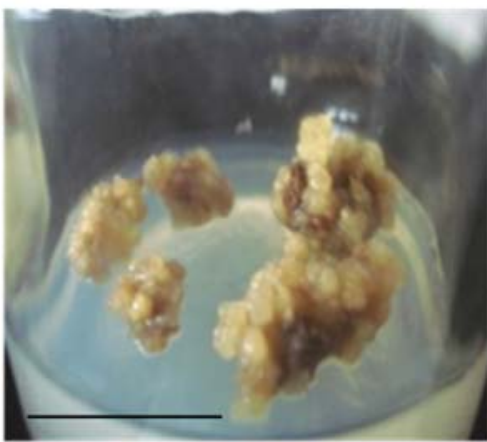

f

Figure 3. Transformed callus on subcultured-1 (a), subcultured-2 (b), subcultured-3 (c), subcultured-4 (d), subcultured-5 (e), and untransformed callus (f), Bar $=10 \mathrm{~mm}$ 

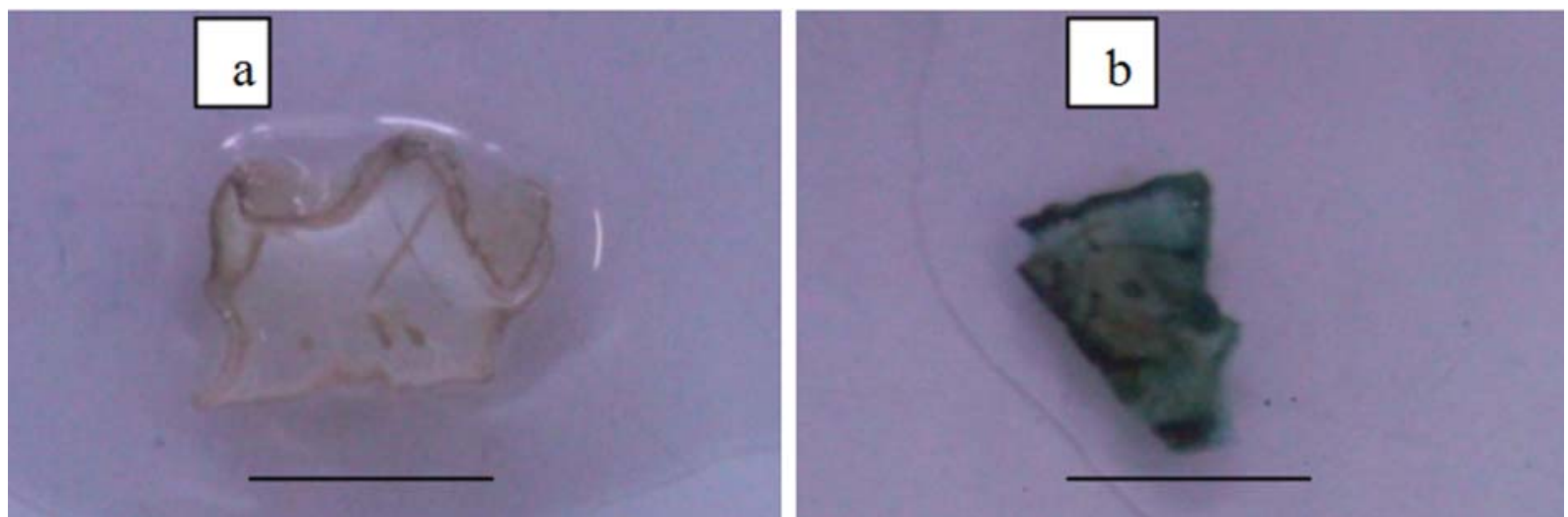

Figure 4. Results of GUS assay of non-transformed leaf disk (a) and transformed leaf disk (b), Bar= $10 \mathrm{~mm}$
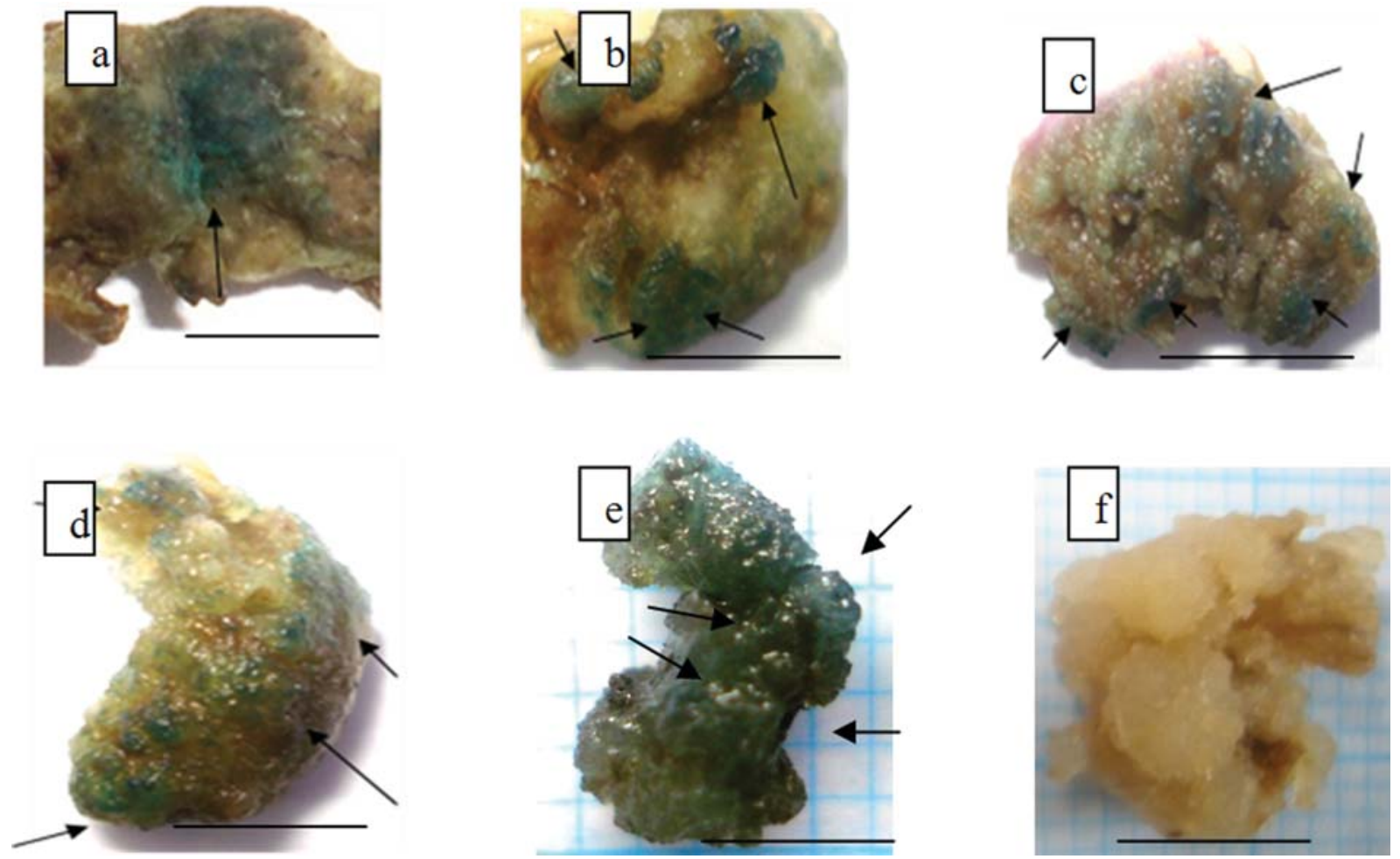

Figure 5. Results of GUS assay in transformed callus on subculture 1-5 (a-e) and untransformed callus (f), the arrow indicates GUS positive expression, $B a r=10 \mathrm{~mm}$

by blue staining spots on almost entire of surface area of the explants, however GUS expression was not detected in non-infected leaf explants (Figure 4). This positive transient expression of GUS indicated the efficiency of T-DNA delivery from $A$. tumefaciens into leaf explants of $A$. paniculata.

The results of GUS histochemical assay in putative transformed callus on subculture $1,2,3,4$, and 5 showed blue staining spots in many callus, however some of the callus showed unstained areas which suggested that some of the putative transformed callus were chimeric. On the other hand, GUS assay for uninfected callus that had been cultured on callus induction medium without hygromycine resulted no blue staining spots (Figure 5). Tripathi et al. (2005) reported the same results in the histochemical assay for GUS for stable expression in transgenic 
leaves of Banana that showed chimeric phenomenon. They thought the cells involved in the bud developments only partially were transformed. This phenomenon was also reported by Hiei et al. (1994) that the blue staining spots was not uniform at the hygromycin-resistant cell colonies because of the uneven process of the transformation that occurs.

In this experiment, GUS expression in callus on subculture- 5 showed the blue staining spots almost uniformly throughout the callus (Figure 5e). This indicates that the cells of transformed callus have been selected by repeated subculture. The nontransformed cells were eliminated but the transformed callus was kept to give rise uniform cells that contain GUS gene. Therefore, it is assumed that the growing callus was transgenic callus. To confirm this assumption, molecular analysis of transgene (GUS gene) that has been subjected into leaf disks together with hpt gene were performed by PCR analysis.

\section{PCR analysis of putative transformed tissue}

In this experiment, transformed callus was obtained after being selected on selection medium (MS medium containing hygromycin). The calli on the first to fifth subculture were survive and continuously divided. These suggested that T-DNA from pCAMBIA1304 plasmid has been integrated into the calli. To confirm the presence of T-DNA in the callus, a molecular analysis through PCR amplification has been carried out by detection the GUS gene. The results of PCR amplification demonstrated the presence of $976 \mathrm{bp}$ fragment of the GUS gene in all putative transformed calli from subculture 1 to 5 . On the other hand, corresponding fragment was not detected in non-transformed callus (Figure 5). These results indicated that the T-DNA of pCAMBIA1304 plasmid in A. tumefaciens has been integrated into calli of $A$. paniculata on subculture 1,2,3,4, and 5 (approximately within 15 weeks of culture). Those findings led to the thought that callus of A. paniculata has been stably transformed.

This phenomenon seems consistent with the earlier report by Yusibov et al. (1994) that explained that the T-DNA can be found in cytoplasm within 30 minutes after co-cultivation, but after two hours of cocultivation the T-DNA declined because the T-DNA was either degraded or transported into the nucleus and integrated into the genome of plant cell. In this experiment, T-DNA carrying GUS gene appeared in transformed callus on subculture 1,2,3,4, and 5 or within 15 weeks of culture. Thus, this work confirmed that callus of $A$. paniculata has successfully been transformed. Similarly, Mc. Cormick et al. (1986) reported that through a long selection of putative transformed tissue on selection medium, a stable transformation of the tissue can be obtained. In this investigation, the putative transformed callus demonstrated the presence of GUS gene on subculture one to five or within 15 weeks of culture in selection medium. Thus, this results indicated that stable transformation in callus of $A$. paniculata has been obtained through A.tumefaciens mediated transformation that carries GUS gene in pCAMBIA1304 plasmid.

\section{Conclusion}

In conclusion, efficient protocol for genetic transformation of $A$. paniculata mediated by $A$. tumefaciens strain LBA4404 was established to give rise stable transgenic callus. This was indicated by expression of $\beta$-glucuronidase (GUS) and hygromycin phosphotransferase (hpt) genes in transformed callus from first subcultured to fifth subcultured within 15 weeks period. Moreover, molecular analysis through PCR amplification demonstrated the presence GUS gene (976 bp fragment) in the transformed callus from first subcultured to fifth subcultured which confirm the stable transformation of callus $A$. paniculata. Therefore, this reliable transformation 

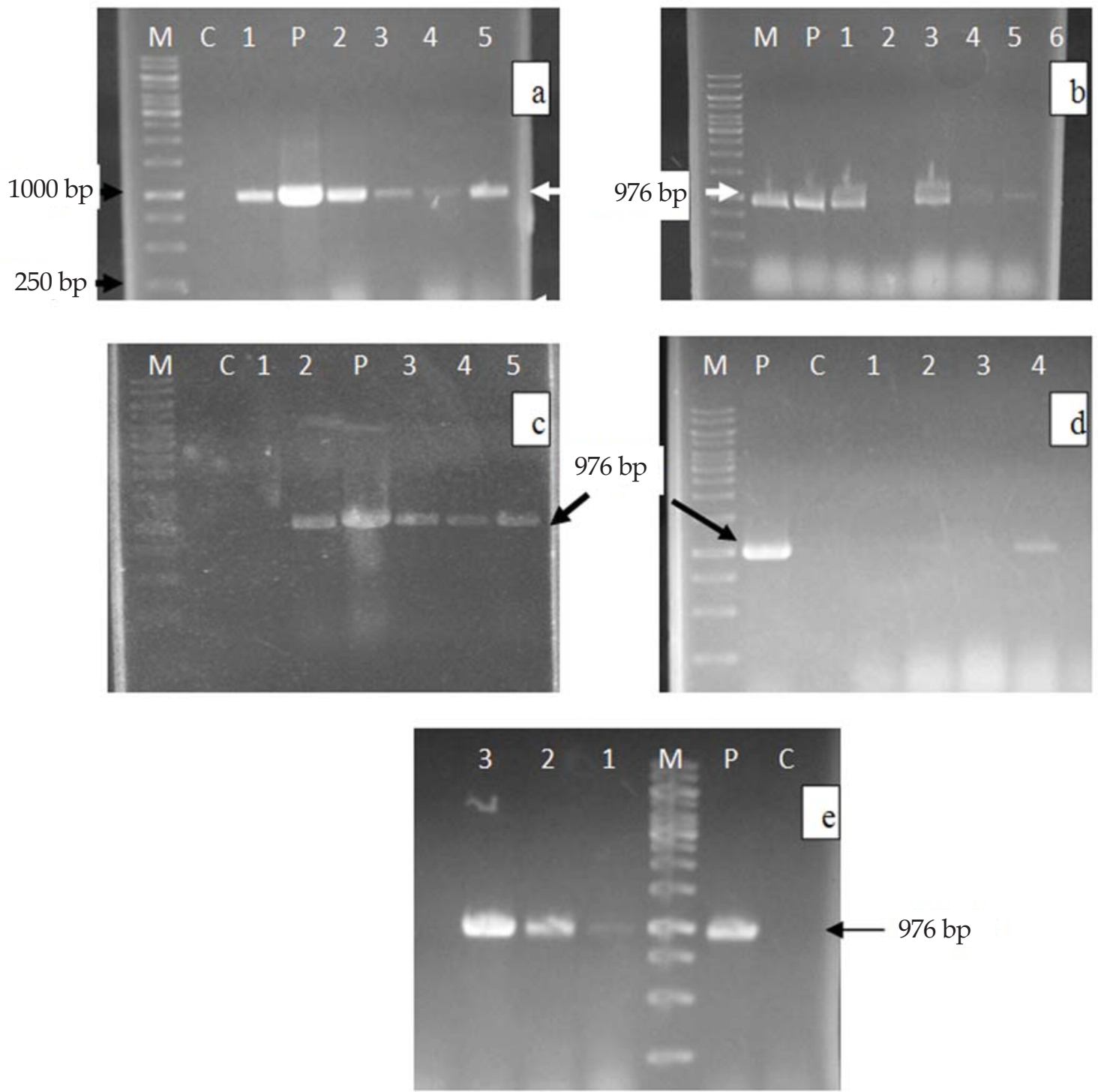

Figure 6. PCR analysis of the genomic DNA from transformed callus using primer amplifying $976 \mathrm{bp}$ fragment of the GUS gene that presence in transformed callus (lane 1-6) on subculture 1 to 5 (a-e). Lane M (molecular weight marker), C (nontransformed callus) , P (pCAMBIA1304).

protocol using A. tumefaciens strain LBA4404 can be applied for transferring any genes of interest into A. paniculata tissue to produce transgenic cell, callus and whole plants with a particular characteristics.

\section{Acknowledgement}

This work was funded by the Priority Research Program of The Research Center in Biotechnology , Institut Teknologi Bandung, Indonesia.

\section{References}

Boyko, A., Matsuoka, A., Kovalchuk, T., 2009. High Frequency Agrobacterium tumefaciens-mediated plant transformation induced by ammonium nitrate. Plant cell Rep., 28, 737-757.

Calabrese, C., Berman, S.H., Babish, J.G., Ma, X., Shinto, L., Dorr, M., Wells, K., Wenner, C.A., Standish, L.J., 2000. A Phase I Trial of Andrographolide in HIV Positive Patients and Normal Volunteers, Phytotherapy Res., 14, 333-338. 
Gelvin, S. B., 2000. Agrobacterium and Plant Genes Involved in T-DNA Transfer and Integration, Ann. Rev. Plant Physiol. Plant Mol. Biol., 51, 223-256.

Hiei, Y., Ohta, S., Komari, T., Kumashiro, T., 1994. Efficient Transformation of Rice (Oryza sativa L.) Mediated by Agrobacterium and Sequence Analysis of the Boundaries of the T-DNA, Plant J., 6(2), 271-282.

Hong, H.P., Zhang, H., Olhoft, P., Hill, S., Wiley, H., Toren, E., Hillebrand, H., Jones, T., Cheng, M., 2007. Organogenic Callus As The Target For Plant Regeneration and Transformation via Agrobacterium in Soybean (Glycine max (L.) Merr.), In Vitro Cell. Dev. Biol. Plant. 43, 558-568.

Hui Li, L., Yang J., Qui, H.L., Liu, Y.Y., 2010. Genetic transformation of Physcomitrella patens mediated by Agrobacterium tumefaciens. Afr. J. Biotechnol., 9(25), 3719-3725.

Li, Z.T., Gray, D.J., 2005. Genetic Engineering Technologies. In Plant Development and Biotechnology (R.N. Trigiano and D.J. Gray, eds) pp 241-250, CRC Press.

Li, HQ., Xu, J., Chen, L., Li, MR., 2007. Establishment of an Efficient Agrobacterium tumefaciens-mediated Leaf Disc Transformation of Thellungiella halophila, Plant Cell Rep., 26, 1785-1789.

Lodhi, M.A., Guang-Ning Ye, Norman F.W., Bruce, I.R., 1994. A Simple and efficient method for DNA extraction from grapevine cultivars, Vitis species and Ampelopsis. Plant Mol. Biol. Rep., 12(1), 6-13

Mulabagal, V., Tsay, H.S., 2004. Plant cell cultures-an alternative and efficient source for the production of biologically important secondary metabolites, Intl. J. Appl. Sci. and Eng., 2(1), 29-48

Mc Cormick, S., Niedemeyer, J., Fry, J., Barnason, A., Horsch, R., Fraley, R., 1986. Leaf disc transformation of cultivated tomato (L.esculentum) using Agrobacterium tumefaciens, Plant Cell Rep. 5, 81-84.
Niranjan, A., Tewari, S.K., Lehri, A., 2010. Biological Activities of Kalmegh (Andrographis paniculata Nees) and Its Active Principles - A Review, Ind. J. Nat. Prod. and Resources., 1, 125-135.

Otake, T., Mori, H., Morimoto, M., Ueba, N., Sutardjo, S., Kusumoto, I.T., Hattori, M., Namba, T., 1995. Screening of Indonesian Plant Extracts for AntiHuman Immunodeficiency Virus-Type 1 (HIV-1) Activity, Phytotherapy Res., 9, 6-10.

Serres, R., McCown, B., Zeldin, E., 1997. Detectable $\beta$-glucuronidase Activity in Transgenic Cranberry is Affected by Endogenous Inhibitors and Plant Development, Plant Cell Rep., 16, 641646.

Sharma, M.K., Solanke, A.U., Jani, D., Singh, Y., dan Sharma, A.K., 2009. A Simple and Efficient Agrobacterium-mediated Procedure for Transformation of Tomato, J. Biosci., 34, 423-433.

Tripathi, L., Tripathi J.N., Hughes, J. d'A., 2005. Agrobacterium-mediated Transformation of Plantain (Musa spp.) Cultivar Agbagba, Afr. J. Biotechnol., 4(12), 1378-1383.

Turhan, A., 2004. Callus induction and growth in transgenic potato genotypes, Afr. J. Biotech., 3(8), 375-378

Vasudevan, A. Selvaraj, N. Ganapathi, A., Choi, C.W., 2007. Agrobacteriummediated genetic transformation in Cucumber (Cucumis sativus L.), Am. J. Biotechnol and Biochem., 3(1), 24-32

Yusibov, V.M., Steck, T.R., Gupta, V., Gelvin, S.B., 1994. Association of Single-stranded Transferred DNA from Agrobacterium tumefaciens with Tobbacco Cells, Proc. Natl. Acad. Sci,. USA., 91, 2994-2998.

Zhang, X., Tan, B.K., 2000. Antihyperglycaemic and Anti-oxidant Properties of Andrographis paniculata in Normal and Diabetic Rats, Clinical and Exp. Pharmacology and Physiol., 27, 358-363. 